\title{
Using a pacifier to decrease sudden infant death syndrome: An emergency department educational intervention
}

Background: Pacifier use decreases the risk of sudden infant death syndrome (SIDS). An emergency department (ED) visit may provide an opportunistic 'teachable moment' for parents. Objectives: To test the hypotheses (1) that caregivers were less familiar with the role of pacifiers in sudden infant death (SIDS) prevention than other recommendations, and (2) that an ED educational intervention would increase pacifier use in infants younger than six months, and (3) that otitis media would not occur more frequently in pacifier users. Methods: An intervention-group-only longitudinal study in a county hospital ED. We measured pacifier use infants and baseline knowledge of SIDs prevention recommendations in caregivers. We followed up three months later to determine pacifier use, and 12 months later to determine episodes of otitis media. Results: We analyzed data for 780 infants. Parents knew of advice against co-sleeping in 469/780 (60\%), smoking in 660/776 (85\%), and prone sleeping in $613 / 780$ (79\%). Only $268 / 777$ (35\%) knew the recommendation to offer a pacifier at bedtime. At enrollment 449/780 (58\%) did not use a pacifier. Of 210/338 infants aged less than 6 months followed up 41/112 (37\%) non-users had started using a pacifier at bedtime (NNT 3). Over the same period, $37 / 98$ (38\%) users had discontinued their pacifier. Otitis media did not differ between users and non-users at 12 months. Conclusion: Caregiver knowledge of the role of pacifiers in SIDS prevention was less than for other recommendations. Our educational intervention appeared to increase pacifier use. Pacifier use was not associated with increased otitis media. 
1 Title: Using a pacifier to decrease sudden infant death syndrome: An emergency department

2 educational intervention.

3 Corresponding Author: Paul Walsh, University of California Davis, Department of Emergency

4 Medicine, 4150 V Street \#PSSB 2100, Sacramento, CA 95817. Email:pfwalsh@ucdavis.edu

5 Telephone 19162711954

6 Authors:

7 Paul Walsh $(1,2)$

8 Teri Vieth, (2)

9 Carolina Rodriguez (2)

10 Nicole Lona (2)

11 Rogelio Molina (2)

12 Emnet Habebo (2)

13 Enrique Caldera (2)

14 Cynthia Garcia (2)

15 Gregory Veazey (2)

\section{Affiliations}

17 (1) University of California Davis, Department of Emergency Medicine, 4150 V Street

$18 \quad$ \#PSSB 2100, Sacramento, CA 95817.

19 (2) Kern Medical Center, 1700 Mt Vernon Avenue, Bakersfield, CA 93306

20 KEYWORDS: Sudden infant death syndrome; pacifier; emergency department; parental

21 education;

22 INTRODUCTION 
23 In 2005 the American Academy of Pediatrics recommended that caregivers should offer infants

24 between one and six months of age a pacifier (dummy, soother, binky) when putting them down

25 to sleep. The recommendation was based on studies(De-Kun et al. 2005, Fleming et al. 1999,

26 Arnestad et al. 1997, Fleming et al. 1996, Hauck et al. 2003) showing pacifier use is associated

27 with decreased risk of sudden infant death syndrome (SIDS). Pacifier use also mitigates the SIDS

28 risk associated with soft bedding and prone sleeping position.(Task Force on Sudden Infant Death

29 2005) Our clinical experience suggested that relatively few parents knew the role of pacifiers in

30 SIDS prevention; on the contrary they feared pacifiers increased ear infections or dental

31 problems.

32 Alcohol abuse and injury prevention research suggest that emergency department (ED) visits

33 represent 'teachable moments' during which educational interventions may be disproportionately

34 effective.(Johnson et al. 2007, Williams et al. 2005) In this case, a potentially effective

35 intervention in the ED could be to recommend offering a pacifier at bed time. Although a

36 randomized controlled trial would be ideal, we felt it unethical to randomize some infants'

37 parents to receive knowledge that could prevent SIDS while withholding it from others.

38 Instead, we performed an intervention only trial in which we associated new pacifier use with

39 (but could not attribute it to) our intervention and controlled for other variables. We

40 conceptualized the conversion of non-user to user as a combination of infant and family factors,

41 our intervention, overall community knowledge (which could vary with time), and knowledge

42 dissemination as a direct result of our intervention.

43 We hypothesized (1) that infant caregivers were less familiar with the role of pacifiers in SIDS

44 prevention than other recommendations, (2) that an ED educational intervention would increase 
45 pacifier use in infants aged between one and six months, and (3) that otitis media would not

46 occur more frequently in infants using pacifiers.

\section{METHODS}

48 Objectives

49 Primary objective

50 To compare self-reported primary caregiver knowledge of the recommendation that pacifier use

51 is associated with decreased SIDS risk with self-reported primary caregiver knowledge of the

52 recommendations that infants should sleep on their backs.

\section{Secondary objectives}

54 To compare knowledge of the pacifier recommendation with other SIDS prevention

55 recommendations; namely that infants should not co sleep with parents, should not have

56 additional blankets or toys in the crib, and that baby should not be exposed to second hand

57 tobacco smoke.

58 To determine what proportion of primary caregivers who received the intervention introduced a

59 pacifier if their infant was aged one to six months and not already using one.

60 To determine if the occurrence of otitis media, or recurrent otitis media differed between pacifier

61 users and nonusers during the 12 months following enrollment.

62 To identify possible associations between caregiver and infant characteristics and knowledge of

63 the pacifier recommendation.

64 To identify possible associations between caregiver and infant characteristics and conversion

65 from pacifier nonuser to user and vice-versa.

\section{Design}


67 We conducted a longitudinal study of an educational intervention between 11/26/2008 and

68 8/1/2011 including a 12 month period of follow up without additional patient accrual.

\section{Setting}

70 The study site was a teaching county hospital with emergency medicine, family practice and

71 OBGYN residencies serving a mixed rural, suburban and urban population.

\section{Subjects}

\section{Inclusion criteria}

74 All infants younger than 12 months of age and their primary caregivers were eligible. Research

75 assistants (RA) worked four or eight hour shifts including nights, weekends and holidays.

76 Because of potentially non-random gaps in RA coverage we considered our sampling to be

77 convenience rather than consecutive.

78 Exclusion Criteria

79 Subjects were excluded for refusal of consent, being in foster care or custody.

\section{Study definitions}

81 Pacifier use was defined as parentally reported use of the pacifier when the infant was being put

82 down to sleep. Knowledge of a particular recommendation was defined as the primary caregiver

83 affirming that they were aware of the recommendation when specifically asked. When parents

84 were uncertain whether or not they knew about a recommendation the answer was classified as

85 missing. We defined early pacifier discontinuation as discontinuation of pacifier use before six

86 months of age in an infant was a pacifier user at enrollment. Otitis media was defined as parental

87 report of a health care provider diagnosing otitis media. Recurrent otitis media was defined as 88 three or more such episodes. 


\section{Outcome measures}

90 Our primary outcome measure was the percentage of primary caregivers who reported being

91 knowing that offering infants between one and six months of age a pacifier at bedtime decreases

92 the risk of SIDS. Our secondary outcome measures included the percentage of primary

93 caregivers with knowledge of the other SIDS prevention recommendations, the percentage of

94 caregivers who started offering their infant a pacifier, (if that infant was aged one to six months

95 and was not already a pacifier user) and parentally reported occurrences of otitis media at 12

96 months following enrollment. Our outcome measures for associations between caregiver and

97 infant characteristics and knowledge of the pacifier recommendation and conversion from

98 pacifier nonuser to user were odds ratios (OR).

\section{Intervention}

100 The survey and educational intervention were administered by an RA or investigator. The initial

101 survey inquired about pacifier use, parental knowledge of SIDS prevention strategies, household

102 characteristics, and other demographic characteristics. The key SIDS-prevention strategies

103 inquired after were: (a) infants should not sleep in the same bed as their parents; (b) infants

104 should sleep on their back, not prone; (c) stuffed toys, comforters, blankets etc. should not be in

105 the crib;(d) parents should not smoke; and (e) infants between one and six months of age should

106 be offered a pacifier when being put down to sleep. This baseline survey was conducted face to

107 face with the primary caregiver and is included as Appendix 1. Prior to implementation, we

108 tested pilot versions to reduce ambiguity.

109 The educational intervention consisted of the RA discussing SIDS prevention with the parents by

110 explaining the contents of a printed color one-page brochure. Spanish speakers or a telephone 
111 translation service was used for Spanish speaking caregivers. This brochure is shown in

112 Appendix 2. After the intervention, the brochure was given to the parents. RAs were trained with 113 two hours of didactic lectures about SIDS and SIDS prevention. They were also trained in study

114 enrollment procedures using scripts, role play sessions, and by observation of a study

115 investigator. RA training was repeated and reinforced regularly during the study.

116 Follow-up telephone calls were made at three and 12 months after enrollment. Five attempts at 117 telephone contact were made on different days and at different times for each subject at each time 118 point. If follow-up failed we checked the coroner's records for vital status. Spanish and English 119 speaking RAs made the follow-up calls. During the three-month follow-up telephone-call, we 120 questioned caregivers about pacifier use and about how many other people they had told of the 121 intervention. At 12-months follow-up, we inquired about the number of episodes of otitis media 122 with which the child had been diagnosed. The initial survey was collected with pen and paper and 123 keyed into a customized Filemaker-pro database (Filemaker Inc, Santa Clara, CA) by RAs. The 124 investigators reviewed all cases for data entry errors. Follow-up data was entered directly into the 125 database during the telephone call.

\section{Statistical methods}

127 Primary outcome

128 We compared knowledge of the pacifier recommendation with the back to sleep and other SIDS 129 prevention recommendations using Fishers exact test.

\section{Secondary outcomes}

131 We attempted to identify infant, caregiver and household characteristics factors associated with 132 pacifier use. We performed univariate analysis of the variables he variables pacifier use started in 
133 the hospital, NICU stay, primary care provider, primary caregiver, self-described primary

134 caregiver race/ethnicity, caregiver age, recollection of prior clinic and discharge education,

135 medical insurance type, number of bedrooms, number of siblings, and their interactions.

136 Variables with a $p$ value of $<0.20$ were considered for multivariable modeling. We ultimately

137 retained only those with a $p$-value of $\leq 0.05$. We used the same approach to identifying factors

138 associated with knowledge of the pacifier and other recommendations.

139 We expected that conversion from pacifier non-user to user between one and six months of age

140 would be a function of (a) infant, caregiver and household characteristics, (listed above) (b)

141 overall community knowledge of the role of pacifiers which could vary with time (a secular

142 trend), (c) knowledge spread among caregivers as a direct result of the intervention and (d) our

143 intervention. We could not directly measure the effect of our intervention without withholding it.

144 We therefore adjusted for the other factors in the same manner as when attempting to identify and

145 associated the remaining effect with our intervention.

146 Secular trends in overall community knowledge

147 We addressed community knowledge by measuring awareness of the role of pacifiers in SIDS

148 prevention in infants up to 12 months of age and comparing the baseline knowledge of newly

149 enrolled caregivers in each four month period of recruitment for each recommendation.

150 Physical proximity

151 We addressed physical proximity by creating two proximity measures defined as the number of

152 prior participants living within five and 20 minutes driving time. Times were calculated using

153 Google maps.(Ozimek and Miles 2011)

154 Social Proximity 
155 We addressed the effect of social proximity, as a proxy for social proximity itself, by asking

156 caregivers at follow-up with how many other people had shared the pacifier recommendations.

157 We included the number of people prior subjects reported telling as a variable in our model.

158 SIDS by definition occurs up to 12 months of age. We included infants up to 12 months of age

159 because we were assessing knowledge of recommendations to prevent SIDS. Because the pacifier

160 recommendation applies only up to six months of age, we limited intervention effect estimates to

161 infants aged less than six months. We included all infants when estimating the effect of pacifier

162 use on the incidence of otitis media.

163 We calculated the efficacy of the intervention as the proportion of non-users who became users

164 and who were younger than six months old at first follow up. We performed an intention to treat

165 analysis for those successfully followed up, but whom because of delays in successfully

166 contacting the caregiver, were actually over six months of age at follow up and a treatment

167 received analysis including those only who were actually under 6 months of age at this follow-up.

168 We used published estimates of the numbers needed to treat (pacifier use) (NNT) to prevent one

169 death from SIDS to estimate of the number of infants whose caregivers would need to be

170 educated to prevent one death from SIDS.(Hauck et al. 2003)

171 We compared the prevalence of parent-reported diagnoses of otitis media, and recurrent otitis

172 media (defined as three or more episodes) between pacifier users and never-users with Fisher's

173 exact test. Some have argued that pacifier use increases the risk for otitis media.(Uhari et al.

174 1996) Our clinical experience also suggested that this was a concern for some parents. Therefore

175 we felt it important to collect data on otitis media despite the fact that it tends to be more

176 common in children over two years of age than in infants. 
177 We compared the characteristics between those in whom follow up was successful and those in

178 whom it was not. We performed post hoc exploratory analysis of factors associated with

179 conversion from pacifier user to nonuser using univariate analysis and logistic regression.

180 We managed and analyzed study data using Stata 12 (Statacorp LLP, College Station TX). Kern

181 Medical Center's institutional review board approved the study. Written informed consent was

182 obtained from the available adult with nearest next of kin.

183 RESULTS

184 We enrolled 799 infants. Nineteen patients were excluded for repeated enrollment. One infant

185 died of SIDS and one of pneumonia. Both were pacifier users at baseline. The primary caregiver

186 was usually the mother or grandmother. The median age of mothers (who were sole caregivers)

187 was 24 (IQR 10); grandmothers were in their 40s-50s (median and mean 50 IQR14). Sample

188 characteristics and baseline pacifier use are detailed in Table 1. Patient flow through the study is

189 shown in Figure 1.

190 Baseline knowledge of SIDS prevention recommendations

191 Caregiver knowledge of recommendations is in Table 2. Pacifier use was the least well known

192 recommendation, 268/777 (35\%), compared with 613/780 (79\%) for supine sleeping $(p<0.001)$.

193 Pacifier was also significantly less well known than any other recommendation $(p<0.001)$.

194 African-Americans had consistently poorer baseline knowledge of the recommendations but

195 made up only $8 \%$ of the sample. Knowledge of one recommendation was associated with

196 knowledge of the pacifier in univariate analysis. This effect was smaller for advice against

197 smoking which appeared to be known to parents regardless of knowledge of other SIDS

198 prevention strategies. All of these effects were weaker in multivariable analysis. These are shown 199 in Appendices 3 and 4. 
201 At baseline 331/780 (42\%) used a pacifier. Among infants aged less than three and 3-6 months 202 pacifier use was 166/338 (49\%) and 71/171 (42\%) respectively. Pacifier use was more frequent 203 among younger infants of younger mothers and among those who been given a pacifier in the 204 hospital.

205 The initiation of pacifier use in the newborn nursery and parental knowledge that pacifiers 206 decrease SIDS were the strongest predictors of pacifier use at enrollment. This suggests that 207 initiating pacifier use in the newborn nursery and telling parents that pacifiers decrease SIDS at 208 that time could be an effective strategy. Increasing infant age decreased the odds of pacifier use 209 ( $9 \%$ per month of life). Older caregivers were also less likely to offer a pacifier (odds decrease $3 \%$ for each additional year of age or $26 \%$ for each additional 10 years of age). These associations with baseline pacifier use are shown in Table 3. Parents also indicated that advice 212 given personally by a physician was highly influential.

\section{Effect of the intervention}

214 We completed three-month follow-up in 496/780 (64\%) patients. The characteristics of those in

215 whom three month follow up failed and was successful are described in Table 5. Those who

216 failed follow up had caregivers who were slightly older and who were less likely to recall being

217 counseled in SIDS prevention strategies either at discharge following birth or in the clinic. These

218 effects disappeared in multivariable analysis. Twelve month follow-up was successful in 391/780

$219(50 \%)$ infants. Follow up tended to be less successful in younger children and with older parents

220 but these effects disappeared in multivariable analysis. Overall pacifier use at three-month follow 
221 up was 192/496 (39\%); this comprised younger infants starting and older infants discontinuing 222 pacifier use (Figure 2).

\section{Intention to treat analysis}

224 Three month follow-up was successful in 210/338 infants who were aged less than three months 225 at enrollment (i.e. aged less than 6 months at follow-up). We contacted $112 / 172(65 \%)$ of 226 previous non users and 98/166 (59\%) baseline pacifier users. Of the nonusers $41(37 \%)$ had 227 started using a pacifier at bedtime. Over the same time period, $37 / 98$ (38\%) users younger than 228 three months had discontinued their pacifier.

\section{Treatment received analysis}

230 Sixty-two infants who were expected to be less than six months of age at three-month follow up 231 were in fact older than six months because of delays in successfully completing follow up.

232 Excluding these infants at three-month follow up; 70/148 (47\%) were pacifier users at 233 enrollment. Following the intervention 33/78 (42\%) of nonusers has started using a pacifier and 234 20/70 (29\%) had discontinued pacifier use.

235 Assuming that none of the nonusers would have spontaneously become users without the 236 intervention, and ignoring any reduction in early pacifier discontinuation attributable to the 237 intervention, we estimate the number of non-pacifier-using infants needed to treat (educate 238 caregiver for infants aged $<3$ months) to gain an additional user is 3, (95\% CI 2, 4). The NNT for 239 pacifier use to prevent one case of SIDS was 2,733, yielding an NNT (educational intervention) 240 to prevent one SIDS case of 8,199.(Hauck et al. 2003) 
241 Only infant age was significantly associated with starting pacifier use after the intervention OR

$2420.77(95 \%$ CI $0.63,0.94)$ i.e. the odds of adoption of a pacifier decreased by $23 \%$ for each

243 additional month of age. Participants reported telling a total of 947(median 1, IQR 3), other

244 individuals about the pacifier recommendation. The number of people told by prior participants

245 did not affect any outcome. We were able to calculate physical proximity for 281,250 participant

246 dyads. We found no association between physical distance between a subject and prior

247 participants and pacifier adoption. We found no effect for secular trend measured in four month

248 intervals. None of the other infant, caregiver or household variables tested had any impact on

249 pacifier adoption.

250 Increasing age was not associated with change in sleeping position but did decrease pacifier

251 uptake.

252 Factors associated with discontinuing pacifier use were infant age, male gender and not initiating

253 pacifier use in the hospital. (Table 6) Because of the small numbers in this subgroup only two of

254 these three simultaneously maintained a $p$ value of less than 0.05 in multivariable analysis. The

255 models however had similar characteristics and are reported in Table 7. Interestingly, starting a

256 pacifier in the hospital prior to discharge was associated with both with a higher rate of pacifier

257 use, (OR 1.75) and less early discontinuation of the pacifier (OR 0.36) This does suggest an easy

258 intervention, namely starting pacifiers in the hospital. While this may not hinder breast feeding in

259 motivated parents, this may not be the case for less motivated mothers and so this decision may

260 need to be individualized.

261 At one year follow up parents reported 156 episodes of otitis media in 391 infants (40\%) with 35

262 (9\%) having three or more infections and eight parents reporting six or more episodes. Overall, 
263 the prevalence of parent-reported otitis media in 'never-users' was indistinguishable from pacifier

264 users. (Fishers exact test $p=0.808$ ). Among never-users there were 18/156 infants with recurrent

265 (three or more episodes of) otitis media compared with 17/112 among any time pacifier users

266 (Fishers exact test $p=0.471$ ). Multivariable regression of the number of episodes similarly

267 showed no significant relationships between any variable tested.

\section{DISCUSSION}

269 Parental knowledge of the role of pacifiers in SIDS reduction was much less than for other SIDS

270 prevention recommendations. Our educational intervention appeared to increase pacifier use. We

271 did not see an association between parent-reported otitis media and pacifier use.

272 Our subjects' knowledge of other parenting practices known to reduce SIDS was at least as good 273 as that reported elsewhere among professional child minders and parents.(Moon and Oden 2003,

274 Moon et al. 2010) Perhaps it is unsurprising that parental knowledge of the role of pacifiers was

275 less than for the other recommendations; the same is true of health care providers.(Moon et al.

276 2007, Eron et al. 2011) The better known recommendations substantially predate the

277 recommendation to use a pacifier. Unlike recommendations against smoking and non-supine

278 sleeping positions; the pacifier recommendation has been controversial.(Fleming et al. 2006)

279 Recommendations to use a pacifier compete with some mothers' and dentists' fears that pacifiers

280 will harm infants' developing mandibles,(Pansy et al. 2008, Vazquez-Nava et al. 2006, Warren et

281 al. 2005) impair breast feeding,(Howard et al. 2003, Scott et al. 2006) or increase otitis media.

282 (Uhari et al. 1996)

283 Educational interventions addressing bed sharing, smoking, and sleeping position have been

284 shown to be effective in changing parental behavior,(Rasinski et al. 2003, Gibson et al. 2000, 
285 Moon et al. 2004) and epidemiological studies show community-wide education decreases SIDS

286 deaths.(Davidson-Rada et al. 1995, Kiechl-Kohlendorfer et al. 2001) The effect size of our

287 intervention on pacifier use was comparable to that of other educational interventions designed

288 to decrease prone sleeping and bed sharing.(Moon et al. 2004) This is encouraging because the

289 change in behavior occurred in the absence of the expansive multi-pronged approach of other

290 successful SIDS prevention interventions. (Davidson-Rada et al. 1995) Moreover the marginal

291 cost of healthcare providers educating parents during their ED visit is low and is feasible in any 292 setting.

293 Implementing an intervention such as ours is not a trivial exercise. The very high NNT to prevent

294 one SIDS case reflects the rarity of SIDS. Consistent with studies of the 'Back to Sleep'

295 campaign, we found during our discussions with parents that they especially value physicians'

296 advice. Further study to determine the efficacy and costs of an opportunistic targeted approach

297 by emergency physicians is warranted.(Willinger et al. 2000) We speculate that individual

298 emergency physicians discussing SIDS prevention strategies, and specifically discussing the role

299 for pacifiers during the history taking, would incur minimal marginal cost and would be much

300 more efficient. This does not detract from the role of primary care providers in instructing parents

301 regarding SIDS prevention strategies.

\section{Limitations}

303 This study has limitations. We assumed new pacifier use was a result of our intervention and

304 discounted delayed pacifier discontinuance that might have resulted from our intervention. This

305 assumes that parents would not discontinue pacifier use as a result of our intervention. We feel 
306 that this is a reasonable assumption. The ideal approach would be to randomize parents to receive

307 this SIDS risk reduction information or not. We felt that withholding information that is known to

308 decrease SIDS to measure the effectiveness of our intervention would be unethical. Even if we

309 were to accept that not providing this information amounted to 'usual care' we would still have

310 had to obtain consent from 'usual care' patients in order to perform the initial and follow-up

311 surveys. Parents might well inquire why pacifier use was being asked after; and would likely be

312 unimpressed if they were being assigned to 'usual care', and that we that intended to withhold

313 lesser known but consistently effective pacifier recommendations to prevent SIDS. It is difficult

314 to conceive how a study design that willfully withheld such information from parents would not

315 damage the trust between researchers and their community. This would be particularly the case

316 should a SIDS case occur in a non-pacifier using infant in the control group. We addressed this

317 limitation as best we could by controlling for other factors that may affect caregiver knowledge.

318 Our analysis of factors associated with adoption and early discontinuation of pacifier was limited 319 by small numbers despite our large overall sample size. Nonetheless our findings that older age 320 decreases pacifier uptake and increases pacifier discontinuation seems reasonable. Moreover we

321 also identified a modifiable risk factor for early discontinuation which was the same as for actual

322 use suggesting internal consistency in our findings. We accepted parental reports as being

323 accurate. However we had no way to verify the veracity of their statements or of actual pacifier

324 use or actual otitis media. We also did not quantify beyond "yes" or "no" for knowledge of each

325 SIDS prevention recommendation. These would however tend to bias our comparisons of

326 caregiver knowledge of different recommendations to the null.

327 We standardized the time to follow-up rather than choosing to follow-up when the child was aged

328 six months. This facilitated assessment of the intervention but was less patient centered. We

329 relied on caregiver reporting and recall of outcomes. Because we used only a single site, external 
validity is unproven. Nonetheless our finding that parental knowledge of other SIDS

331 recommendations was similar to that reported by other investigators supports the external validity

332 of our findings.(Gibson et al. 2000) Our study was powered to demonstrate increased pacifier

333 adoption not a decreased SIDS rate. We did not measure changes in the adoption of other

334 recommendations. Collecting this additional comparative data would have lengthened the

335 interview process and potentially decreased caregiver cooperation. We also had difficulty

336 completing follow-up, a common difficulty in patient populations such as ours. There were some

337 differences between those in whom follow up succeeded and failed. Caregivers in whom follow

338 up failed were less likely to recall receiving SIDS prevention education in either the clinic or the

339 hospital; they were also slightly older. However these differences did not persist in multivariable

340 analysis. Finally, we had to rely on a simple pamphlet without the benefit of language

341 optimization which could have increased efficacy.(Buller et al. 2000)

\section{CONCLUSION}

343 Parental knowledge of the role of pacifiers in SIDS prevention was modest and much less than

344 for other recommendations. Starting a pacifier during prior to hospital discharge after birth was

345 associated with greater use and lower discontinuation rates in the following year. Our broadly

346 targeted ED-based educational intervention was labor intensive but appeared successful in

347 increasing pacifier use. Pacifier use was not associated with increased otitis media. 
349 Table 1.Description of infants, caregivers and their households.

350 Table 2. Baseline knowledge of SIDS prevention recommendations by primary caregivers.

351 Table 3. Factors associated with pacifier use at enrollment.

352 Table 4. Comparison of characteristics of those in whom three- month follow up was successful 353 and those in whom it failed.

354 Table 5. Comparison of pacifier users who did and did not discontinue use before six months of 355 age.

356 Table 6. Multivariable models of factors associated with early discontinuation of pacifier.

\section{Table of Figures}

358 Figure 1. Patient flow through the study.

359 Figure 2. Pacifier use at three-month follow up by age group.

\section{Table of Appendices}

361 Appendix 1 Survey tool used.

362 Appendix 2 Informational brochure provided to parents.

363 Appendix 3. Univariate analysis of factors associated with primary caregiver knowledge of each

364 of five pacifier prevention recommendations.

365 Appendix 4. Multivariable analysis of factors associated with primary caregiver knowledge of 366 each of five pacifier prevention recommendations. 


\section{Figure 1}

\section{Patient flow through the study.}




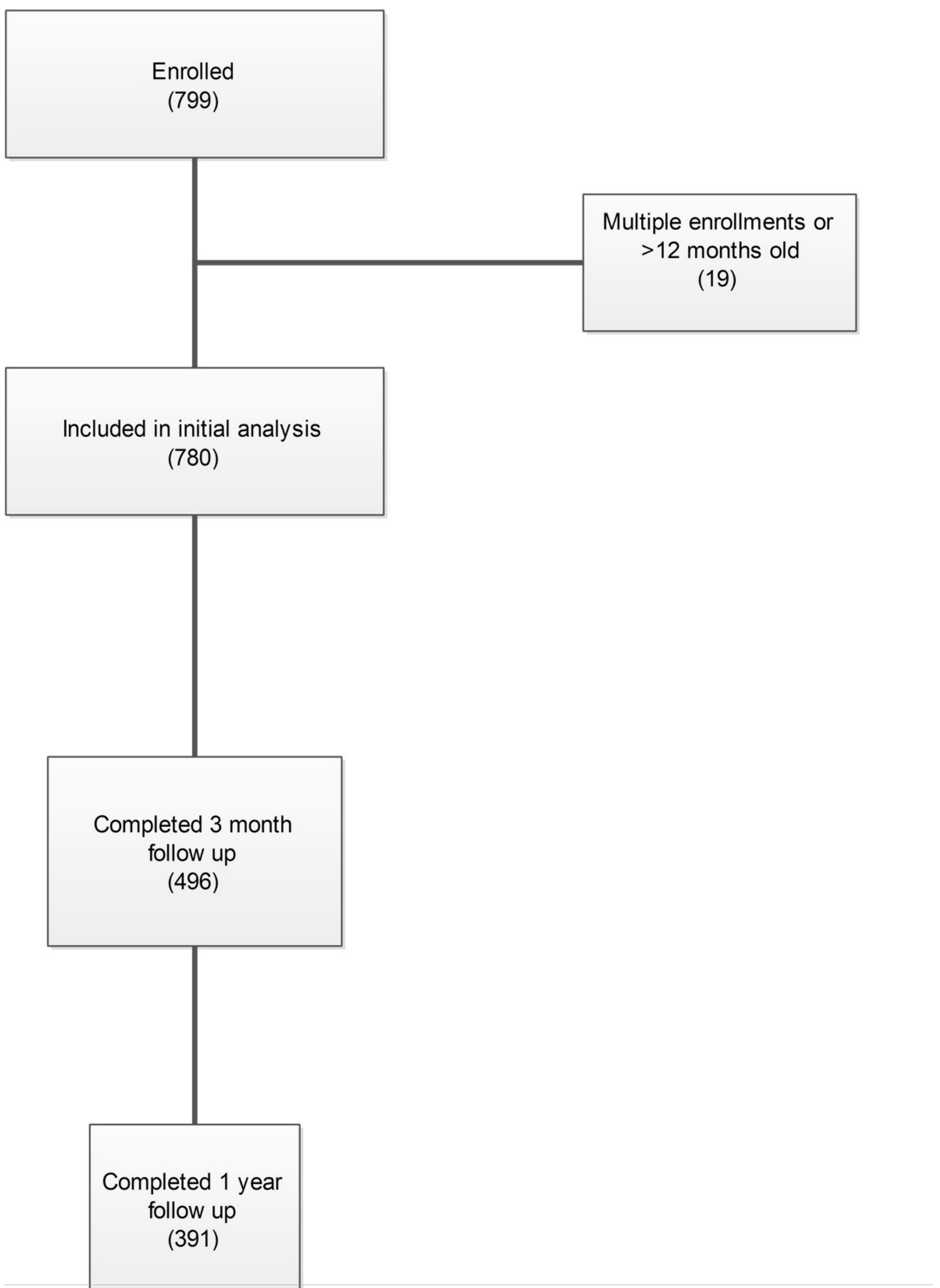




\section{Figure 2}

Pacifier uptake and discontinuance rates by age group.
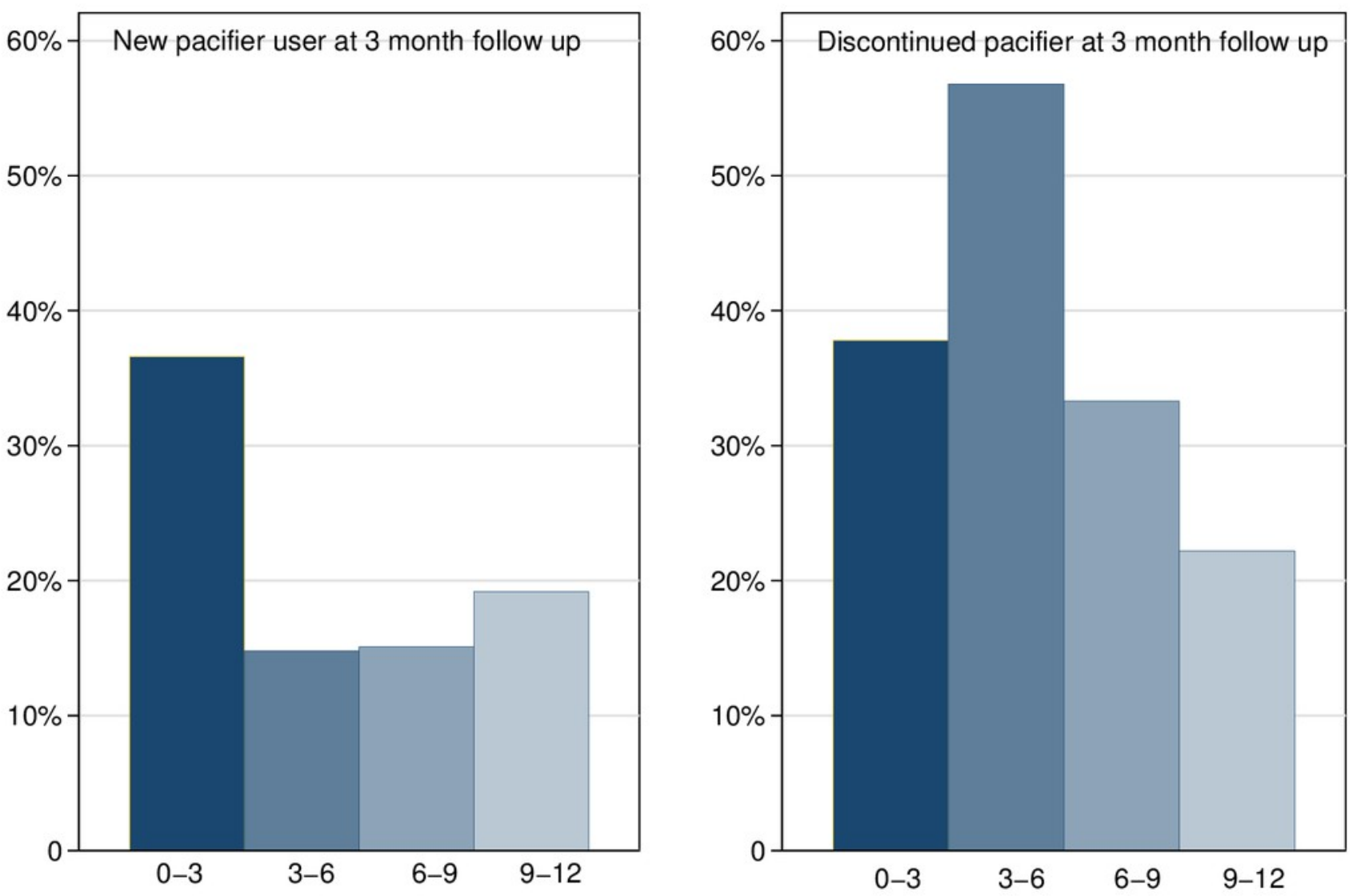


\section{Table 1 (on next page)}

All tables in single file to prevent separation of tables titles and legends 


$\begin{array}{lllccc} & & \text { Number } & (\%) & \text { Median } & \text { IQR } \\ \text { Age } & \text { Total sample (in months) } & 780 & & 3.9 & 6.28\end{array}$

\section{Primary Caregiver}

Mother Alone

Mother \& Father

$608 \quad 78$

Grandmother Alone

$29 \quad 4$

Grandmother \& Mother

$15 \quad 2$

Other

$90 \quad 11$

Father alone

$38 \quad 5$

$0 \quad 0$

\section{Insurance}

Medi-Cal

Private

Uninsured

Declined to answer

$\begin{array}{rr}656 & 84 \\ 22 & 3 \\ 32 & 4 \\ 70 & 9\end{array}$

\section{Pacifier use}

(Younger 6 months at enrollment)

$509 \quad 65$

Uses Pacifier when sleeping

Never

$271 \quad 53$

Sometimes

$166 \quad 33$

Usually

$30 \quad 6$

Always

42

8

Table 1. Description of infants, caregivers and their households. Description of infants, caregivers and their households. Medi-Cal is Medic-Aid in California 


\begin{tabular}{|c|c|c|c|c|c|c|c|c|c|}
\hline \multirow{2}{*}{ 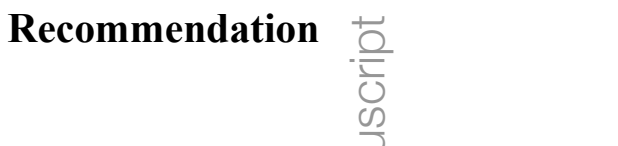 } & \multirow{2}{*}{$\begin{array}{l}\text { Overall } \\
\text { n }\end{array}$} & \multicolumn{3}{|c|}{ First Child } & \multirow{2}{*}{$\begin{array}{l}\geq 3 \text { children } \\
n(\%)\end{array}$} & \multicolumn{2}{|c|}{ Carer $\leq 35$ y } & \multicolumn{2}{|c|}{ Carer $>35 y$} \\
\hline & & $(\%)$ & n & $(\%)$ & & n & $\%$ & n & $\%$ \\
\hline 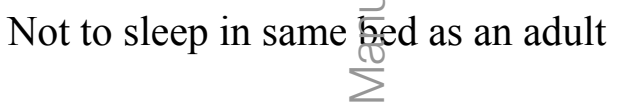 & $469 / 780$ & 60 & $116 / 185$ & 63 & $124 / 21458$ & $339 / 660$ & 59 & $80 / 119$ & 67 \\
\hline Infant to sleep on his & $613 / 780$ & 79 & $143 / 185$ & 77 & $166 / 21478$ & $518 / 661$ & 78 & $95 / 119$ & 80 \\
\hline No blankets, stuffed toys & $589 / 776$ & 76 & $136 / 184$ & 74 & $158 / 21374$ & $500 / 657$ & 76 & $89 / 119$ & 75 \\
\hline Caregivers should nof smoke & $660 / 776$ & 85 & $166 / 183$ & 91 & $178 / 21384$ & $566 / 657$ & 86 & $96 / 119$ & 81 \\
\hline Offer infant pacifier sleep & $268 / 777$ & 35 & $64 / 184$ & 35 & $76 / 21336$ & $223 / 658$ & 34 & $45 / 119$ & 38 \\
\hline
\end{tabular}

Table 2. Baseline knowledge of recommendations by primary caregivers. 


$\begin{array}{ll}\begin{array}{l}\text { Variable } \\ \text { Infants' age (per month) }\end{array} & \begin{array}{l}\text { Odds Ratio (95\% CI) } \\ 0.91(95 \% \text { CI } 0.87-0.95)^{* *}\end{array} \\ \text { Caregivers' age (per year) } & 0.97(95 \% \text { CI } 0.95-0.99)^{* *} \\ \text { Ratio of bedrooms to children } & 1.28(95 \% \text { CI } 1.08-1.53)^{* *} \\ \text { Given pacifier in the hospital } & 1.75(95 \% \text { CI } 1.28-2.40)^{* *} \\ \text { Knew pacifier recommendation } & 1.39(95 \% \text { CI } 1.01-1.92)^{*}\end{array}$

Table 3. Factors associated with pacifier use at enrollment $* \mathrm{p}<0.05 * * \mathrm{p}<0.01$. CI, confidence interval. Ratio of bedrooms to children includes primary caregiver's bedroom 


\begin{tabular}{|c|c|c|c|c|}
\hline Factor & & Follow up failed & Followed up & $p$ \\
\hline $\mathrm{N}$ & & 284 & 496 & \\
\hline Male & & $161(56.7 \%)$ & $270(54.4 \%)$ & 0.54 \\
\hline Age, median (IQR) & months & $3.9(1.2,7.0)$ & $3.91(1.2,8.0)$ & 0.29 \\
\hline \multirow[t]{4}{*}{ Method of feeding at enrollment } & bottle & $163(65.7 \%)$ & $302(61.8 \%)$ & 0.66 \\
\hline & bottle \& solids & $1(0.4 \%)$ & $2(0.4 \%)$ & \\
\hline & breast & $29(11.7 \%)$ & $53(10.8 \%)$ & \\
\hline & solids only & $0(0.0 \%)$ & $1(0.2 \%)$ & \\
\hline Had NICU stay & & $48(19.3 \%)$ & $106(21.5 \%)$ & 0.47 \\
\hline Number of bedrooms, median (IQR) & & $2.5(2,3)$ & $3(2,3)$ & 0.20 \\
\hline Number of siblings, median (IQR) & & $1(1,3)$ & $2(1,3)$ & 0.37 \\
\hline Pacifier started in the hospital & No & $155(55.0 \%)$ & $260(52.6 \%)$ & 0.53 \\
\hline & Missing & $39(13.7 \%)$ & $18(3.6 \%)$ & \\
\hline \multirow[t]{2}{*}{ SIDS counseling at well baby clinic } & No & $150(60.7 \%)$ & $354(72.5 \%)$ & 0.001 \\
\hline & Yes & $97(39.3 \%)$ & $134(27.5 \%)$ & \\
\hline \multirow[t]{2}{*}{ Pacifier user at enrollment } & No & $155(54.6 \%)$ & $294(59.3 \%)$ & 0.200 \\
\hline & Yes & $129(45.4 \%)$ & $202(40.7 \%)$ & \\
\hline
\end{tabular}

Table 4. Comparison of characteristics of those in whom 3 month follow up was successful and those in whom it failed. NICU; Neonatal intensive, SIDS; Sudden infant death syndrome, IQR; interquartile range. SIDS counseling at discharge; refers to discharge after child birth. 


\begin{tabular}{|c|c|c|c|c|}
\hline Factor & & Did not stop & Stopped using pacifier & $p$ \\
\hline $\mathrm{N}$ & & 61 & 37 & \\
\hline Male & & $30(49 \%)$ & $27(73 \%)$ & 0.021 \\
\hline Age, median (IQR) & months & $1.02(0.56,1.69)$ & $1.32(0.93,1.92)$ & 0.340 \\
\hline Age at follow up (months), median (IQR) & months & $4.69(4.10,5.75)$ & $5.95(4.63,6.71)$ & 0.008 \\
\hline \multirow{3}{*}{ Method of feeding at enrollment } & bottle & $32(53 \%)$ & $20(54 \%)$ & 0.980 \\
\hline & breast & $9(15 \%)$ & $5(14 \%)$ & \\
\hline & breast and bottle & $19(32 \%)$ & $12(32 \%)$ & \\
\hline Had a NICU stay & & $16(26 \%)$ & $6(17 \%)$ & 0.280 \\
\hline Number of bedrooms, median (IQR) & & $3(2,3)$ & $3(2,3)$ & 0.750 \\
\hline Number of siblings, median (IQR) & & $2(0,3)$ & $1(1,3)$ & 0.930 \\
\hline \multirow[t]{2}{*}{ Pacifier initiated in hospital } & No & $29(48 \%)$ & $26(70 \%)$ & 0.028 \\
\hline & Yes & $32(52 \%)$ & $11(30 \%)$ & \\
\hline Caregiver age, median (IQR) & Years & $24(20,30)$ & $22(20,28)$ & 0.480 \\
\hline \multirow[t]{3}{*}{ SIDS counseling at discharge } & No & $37(61 \%)$ & $24(65 \%)$ & 0.910 \\
\hline & Yes & $22(36 \%)$ & $12(32 \%)$ & \\
\hline & Missing & $2(3 \%)$ & $1(3 \%)$ & \\
\hline \multirow[t]{2}{*}{ SIDS counseling at well baby clinic } & No & $45(75 \%)$ & $29(83 \%)$ & 0.370 \\
\hline & Yes & $15(25 \%)$ & $6(17 \%)$ & \\
\hline Number of bedrooms, median (IQR) & & $3(2,3)$ & $3(2,3)$ & 0.750 \\
\hline \multirow[t]{2}{*}{ Fed by bottle only (at enrollment) } & 0 & $28(47 \%)$ & $17(46 \%)$ & 0.940 \\
\hline & 1 & $32(53 \%)$ & $20(54 \%)$ & \\
\hline
\end{tabular}

Table 5. Comparison of pacifier users who did and did not discontinue use before six months of age. NICU; Neonatal intensive, SIDS; Sudden infant death syndrome, IQR; interquartile range. SIDS counseling at discharge; refers to discharge after child birth. 


\begin{tabular}{|c|c|c|c|c|c|c|}
\hline Factor & $\begin{array}{c}\text { OR } \\
(95 \% \mathrm{CI})\end{array}$ & $p$ & $\begin{array}{c}\text { OR } \\
(95 \% \mathrm{CI})\end{array}$ & $p$ & $\begin{array}{c}\text { OR } \\
(95 \% \mathrm{CI})\end{array}$ & $p$ \\
\hline $\begin{array}{c}\text { Pacifier started in } \\
\text { hospital }\end{array}$ & $\begin{array}{c}0.43 \\
(0.16,1.10)\end{array}$ & 0.079 & $\begin{array}{c}0.362 \\
(0.15,0.90)\end{array}$ & 0.028 & & \\
\hline Male & $\begin{array}{c}2.50 \\
(0.97,6.43)\end{array}$ & 0.058 & & & $\begin{array}{c}2.96 \\
(1.17,7.44)\end{array}$ & 0.021 \\
\hline Age at follow up & $\begin{array}{c}1.28 \\
(1.04,1.58)\end{array}$ & 0.019 & $\begin{array}{c}1.27 \\
(1.04,1.55)\end{array}$ & 0.017 & $\begin{array}{c}1.29 \\
(1.05,1.60)\end{array}$ & 0.002 \\
\hline \multicolumn{7}{|l|}{ Model } \\
\hline Pseudo $\mathrm{R}^{2}$ & 0.1228 & 0.002 & 0.094 & 0.002 & 0.098 & 0.002 \\
\hline AIC & 1.250 & & 1.262 & & 1.256 & \\
\hline $\mathrm{BIC}$ & -316.507 & & -317.854 & & -318.441 & \\
\hline
\end{tabular}

Table 6. Multivariable models of factors associated with early discontinuation of pacifier. The differences between these models is slight. OR; odds ratio, AIC; Akaike information criteria, BIC; Bayesian information criteria 


\section{Initial Questionnaire}
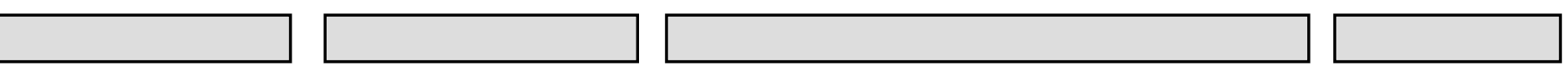

If other, specify

(4) Primary Caregiver?

(5) Age of primary caregiver?

$\square$ Mother $\square$ Father $\square$ Grandmother $\square$ other

(6) Race of primary caregiver?

(if twoprimary caregiver use oldest)

(7) Insurance type

$\frac{\mathcal{S}}{2}$ (8) How many other children in home

(9) Number of bedrooms

(10) Baby's birth date (from other screen)

(11) Clinic Name

(12) Did baby stay in NICU?

(13) Did nurse/doctor discuss SIDS at discharge?

(14) Has doctor discussed SIDS at checkups?

If other, specify

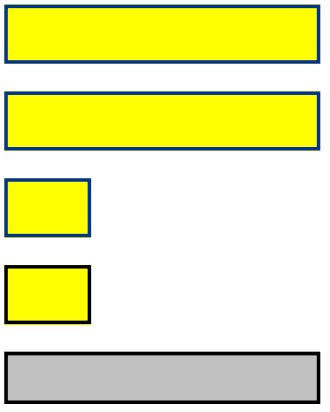

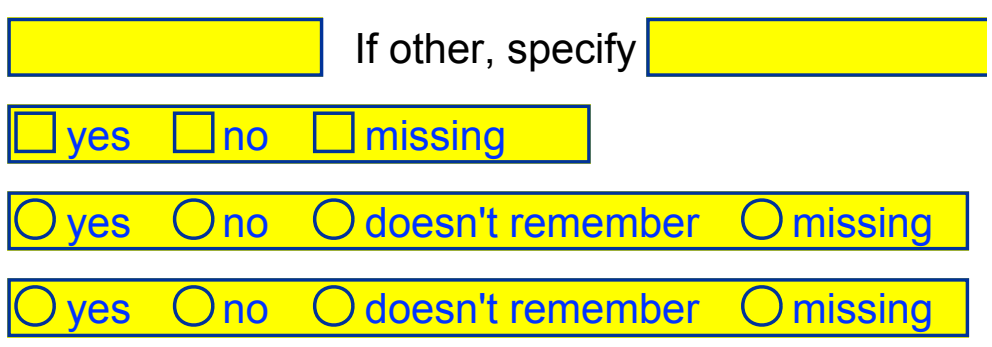

(15) Which of the following were recommended:
(a) Baby not sleep with adults?
(b) Place baby on back?
(c) No loose blankets?
(d) No smoking?
(e) Place pacifier in mouth to sleep?

(16) Given a pacifier by hospital or doctor?

(17) Does baby have pacifier?

(18) Does baby sleep with pacifier?

(19) If pacifier used, why?

\begin{tabular}{|lll|}
\hline Oyes & Ono & Omissing \\
\hline \hline Oyes & Ono & Omissing \\
\hline \hline Oyes & Ono & Omissing \\
\hline \hline Oyes & Ono & Omissing \\
\hline \hline Oyes & Ono & Omissing \\
\hline \hline Oyes & Ono & Omissing \\
\hline \hline Oyes & Ono & Omissing \\
\hline \hline
\end{tabular}

(20) If pacifier not used, why?

If other, specify

(21) How is baby fed? If other, specify 
Hello, my name is <your name> and I am a research assistant at Kern Medical Center. I am trying to reach:

If person is not reached:

Thank you for your time. We will try another day

\section{If person is reached:}

Hi I just had a few questions regarding your last visit to the er with (insert child's name) on

. When you came one of our Research Assistants talked to you about Sudden Infant

Death Syndrome. I just wanted to know (proceed to ask questions):

(1) How many people did you tell about pacifier use to prevent Sudden Infant Death Syndrome?

(2) Does your baby use a pacifier now?

(3) If a pacifier is not used during sleep, which of the following is the reason?

If other, please specify:

(4) Does your baby sleep on its back?
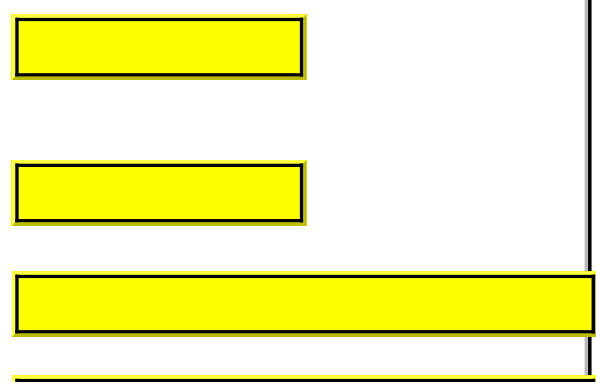

All 5 follow up phone calls failed?

$\square$ yes $\square$ no $\square$ missing

Follow up letter sent date:

Is 3 month follow up successful?

Oyes $\bigcirc$ no $\bigcirc$ missing

Follow up call 1 date

Follow up call 2 date

Follow up call 3 date

Follow up call 4 date

Follow up call 5 date

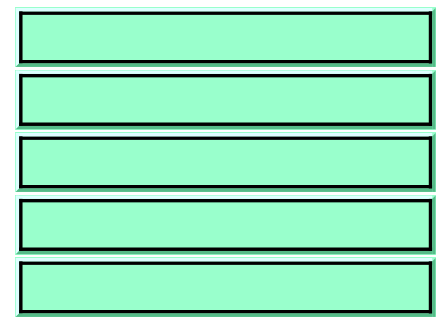

RA Name call 1

RA Name call 2

RA Name call 3

RA Name call 4

RA Name call 5

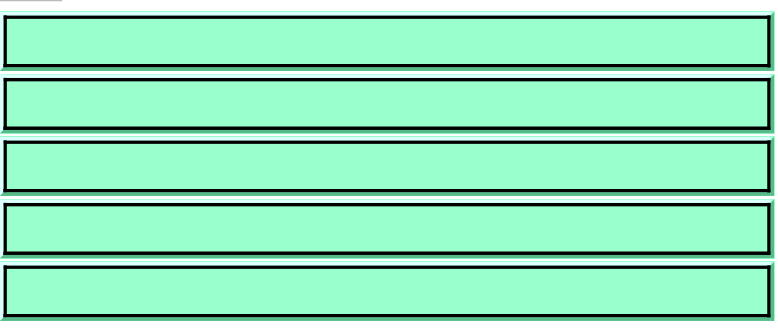

Questionnaire

goto Demographics

Opening Screen 
Hello, my name is <your name> and I am a research assistant at Kern Medical Center. I am trying to reach:

If person is not reached:

Thank you for your time. We will try another day

\section{If person is reached:}

Hello, we are calling to thank you for filling in the survey about Sudden Infant Death Syndrome on $\frac{\text { of }}{2}$ taking the time to answer a few more questions?

(1)How many ear infections has your child had?

(2)Did your baby haveany episoedes of turning blue or stopped breathing since we first told you about the study

(3) Did your baby die of SIDS ?

(4) Has your baby any other medical problems?

What are they?

(5) How is vour child doina overall?

All 5 follow up phone calls failed? $O$ yes $O$ no $O$ missing

Follow up letter sent date:

Is one year follow up successful?

Oyes Ono Omissing

Follow up call 1 date

Follow up call 2 date

Follow up call 3 date

Follow up call 4 date

Follow up call 5 date

follow_up_questions_one_year

pacifier_f_call_q5_year
RA Name call 1

RA Name call 2

RA Name call 3

RA Name call 4

RA Name call 5
Oyes Ono Om

Oyes Ono Om

Oyes Ono Om 
- Don't force your infant to suck on the pacifier

- If you child is being breast fed, wait until he/she reaches one month of age before giving them a pacifier.

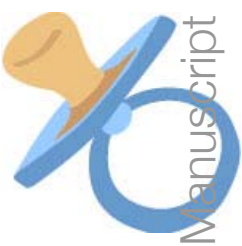

\section{Los Chupones y SIDS}

Estudios han demonstradorque el usode chupones para bebés 12 ineses y menores disiminuido el riesgo de SDDS (Síndrome de Muerte Súbita Infarini). Se recomienda altamente qu le dé un chupón a su bebé antes de dormi Pero, no ponga el chupón en la boca de $\mathrm{A}$. -bebé si ya está dormido son él.

\section{Cosas que se Deben de Observar:}

- Use un chupón limpio

- Cambie el chupón regularmente

- No le ponga nada dulce al chupón

- No forcé el chupón en la boca de su bebé

- Espera que su bebé cumpla un mes para usar el chupón si es que le esta dando pecho
Kern Medical Center's Emergency

Department research staff tries to educate their patients and the public about ways to reduce Sudden Infant Death Syndrome (SIDS). Please help save the lives of our children by spreading the word about SIDS prevention. Thank you...

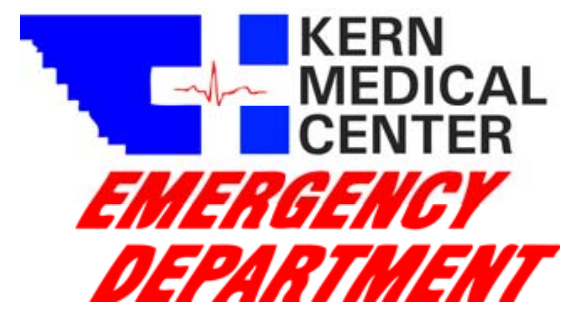

El Centro Medico de Emergencia de el Conado de Kern esta tratando de educar a pacientes y al publico las maneras de cómo reducir el riesgo de Síndrome de Muerted Súbita Infantil (SIDS). Por favor ayúdenos a salvar la vida de nuestros nuestros niños pasando esta información a los demás. Muchas gracias...

\section{Sudden Infant Death Syndrome (SIDS) \\ Prevention}
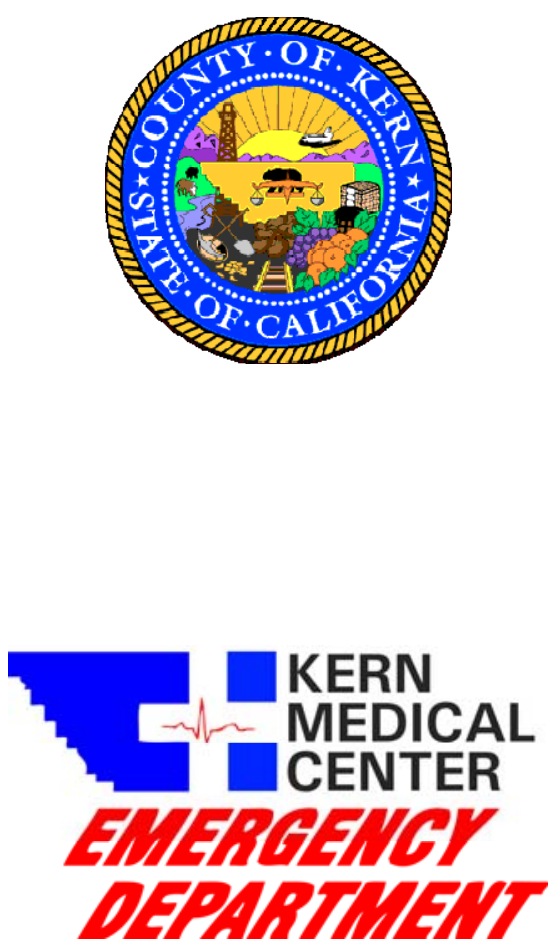

Website/Pagina de Internet: www.kmcemed.edu 


\section{What is Sudden Infant Death Syndrome?}

Sudden Infant Death Syndrome (SIDS) occurs when an infant younger than one of age suddenly dies from an unknown cause.

¿Que es el Sídrome de Mữerte Súbita Infantil?

El Síndrome de Muerte Súbirta Infantil (SIDS), también conocido ềmo la muerte de cuna, es cuando un infairi de 12 meses de edad ó menos muere repæntinamente de causa desconocida.

\section{Sleeping Postitions \& SIDS Prevention} (a)

One of the most importan things you can do to help reduce the risk of SIDS is to lay your healthy baby on his or her back when putting him or her to sleep. Do this when your baby is being put down for a nap or to bed for the night. You may also turn your baby's head to either side.

The American Academy of Pediatrics recommends that babies sleep on their backs unless your doctor instructs you otherwise

Other ways to reduce the risk of SIDS

include:

- Use a crib

- Don't use props, pillows, or anything else

to hold baby in crib

- Avoid overdressing or overheating baby
- Avoid having your baby sleep with you if you are using drugs, alcohol, or cigarettes

- Avoid smoking around baby

- Don’t use alcohol or drugs

* Be sure that anyone caring for you baby knows these guidelines.

\section{Posición Para Dormir y Prevención del $\underline{\text { SIDS }}$}

Una de las cosas mas importantes que usted puede hacer para reducir el riesgo de SIDS es colocar a su bebé sano para dormir boca arriba. Cóloquelo de esta manera cada vez que ponga a su bebé a la cuna para dormir una siesta ó por la noche. Usted puede doblar la cabeza del bebé hacia uno de los lados.

\section{La Academia Americana de Pediatría} recomienda que los bebés duerman de esta manera, a no ser que su medico le haya dada otras intrucciones.

\section{$\underline{\text { Otros modos de reducir el riesgo de SIDS }}$} son:

- Use una cuna

- No use almohadas, reclinadores, ó cualquier otra cosa para sujetar al bebé dentro de la cuna

- Evite vestir ó calendar desmasiado al bebé

- Evite que el bebé duerma con usted si usa drogas, alcohol, ó fuma

- No fume cerca de el bebé

- No use drogas ó alcohol

* Asegúrese que todas las personas que cuidan a su bebé sigan estas direcciones.

\section{Best Sleep Position}

Make sure your baby goes to sleep on his or her back, as this provides the BEST protection against SIDS.

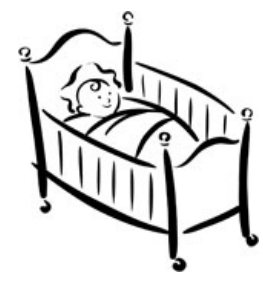

\section{La Mejor Posición}

Asegúrese que su bebé duerma boca arriba. Esto provee la mejor protección contra el SIDS.

\section{$\underline{\text { Pacifiers \& SIDS }}$}

Studies have shown that the use of pacifiers for babies 12 months and younger has decreased the rate of SIDS (Sudden Infant Death Syndrome). It his highly recommended that you give your infant a pacifier before a nap or sleep. Do not place the pacifier into your baby's mouth if they are already asleep without one.

\section{Things to Watch Out For:}

- Make sure to use a clean pacifier

- Replace pacifier on a regular basis

- Don't dip the pacifier into/onto

anything sweet 


\section{Appendix 3}

Univariate analysis of factors associated with primary caregiver knowledge of each of five pacifier prevention recommendations.

\begin{tabular}{|c|c|c|c|c|}
\hline Factor & & Did not know & Knew & $p$-value \\
\hline $\mathrm{N}$ & & 167 & 613 & \\
\hline Male & & $94(56.3 \%)$ & $337(55.0 \%)$ & 0.76 \\
\hline Age, median (IQR) & months & $3.0(0.8,67)$ & $4.1(1.3,7.7)$ & 0.015 \\
\hline Age of primary caregiver, median (IQR) & years & $25(21,31)$ & $25(20,31)$ & 0.33 \\
\hline Primary Caregiver $>35$ years & & $24(14.4 \%)$ & $95(15.5 \%)$ & 0.72 \\
\hline Started pacifier in the hospital & & $57(34.1 \%)$ & $304(49.9 \%)$ & $<0.001$ \\
\hline SIDS counseling at discharge & & $41(26.8 \%)$ & $276(48.4 \%)$ & $<0.001$ \\
\hline SIDS counseling in the clinic & & $27(17.1 \%)$ & $204(35.4 \%)$ & $<0.001$ \\
\hline Number of bedrooms at home median (IQR) & & $2(2,3)$ & $3(2,3)$ & 0.13 \\
\hline Number of other children, median (IQR) & & $1(0,3)$ & $2(1,3)$ & 0.63 \\
\hline Pacifier user at enrollment & & $63(37.7 \%)$ & $268(43.7 \%)$ & 0.16 \\
\hline \multicolumn{5}{|l|}{ Other recommendations known } \\
\hline Not in bed with adult & & $50(29.9 \%)$ & $419(68.5 \%)$ & $<0.001$ \\
\hline No blankets, stuffed animals & & $73(43.7 \%)$ & $516(84.7 \%)$ & $<0.001$ \\
\hline No smoking & & $110(66.7 \%)$ & $550(90.0 \%)$ & $<0.001$ \\
\hline Pacifier when sleeping & & $38(22.8 \%)$ & $230(37.7 \%)$ & $<0.001$ \\
\hline
\end{tabular}

\begin{tabular}{|c|c|c|c|c|}
\hline Factor & & Did not know & Knew & p-value \\
\hline $\mathrm{N}$ & & 310 & 469 & \\
\hline Male & & $173(55.8 \%)$ & $257(54.8 \%)$ & 0.78 \\
\hline Age, median (IQR) & months & $3.4(1.0,7.2)$ & $4.2(1.4,7.85)$ & 0.075 \\
\hline Age of primary caregiver, median (IQR) & years & $25(21,30)$ & $25(21,31)$ & 0.60 \\
\hline Primary Caregiver $>35$ years & & $39(12.6 \%)$ & $80(17.1 \%)$ & 0.089 \\
\hline Started pacifier in the hospital & & $118(38.2 \%)$ & $242(51.9 \%)$ & $<0.001$ \\
\hline SIDS counseling at discharge & & $88(30.1 \%)$ & $228(53.0 \%)$ & $<0.001$ \\
\hline SIDS counseling in the clinic & & $57(19.3 \%)$ & $174(39.6 \%)$ & $<0.001$ \\
\hline Number of bedrooms at home median (IQR) & & $3(2,3)$ & $3(2,3)$ & 0.059 \\
\hline Number of other children, median (IQR) & & $1(1,3)$ & $1(1,3)$ & 0.47 \\
\hline Pacifier user at enrollment & & $130(41.9 \%)$ & $201(42.9 \%)$ & 0.80 \\
\hline \multicolumn{5}{|l|}{ Other recommendations known } \\
\hline Sleeps on back & & $193(62.3 \%)$ & $419(89.3 \%)$ & $<0.001$ \\
\hline No blankets, stuffed animals & & $183(59.2 \%)$ & $405(86.9 \%)$ & $<0.001$ \\
\hline No smoking & & $237(77.2 \%)$ & $422(90.2 \%)$ & $<0.001$ \\
\hline Pacifier when sleeping & & $78(25.2 \%)$ & $189(40.5 \%)$ & $<0.001$ \\
\hline
\end{tabular}




\begin{tabular}{|c|c|c|c|c|}
\hline \multicolumn{5}{|l|}{ No blankets/stuffed toys in crib } \\
\hline Factor & & Did not know & Knew & p-value \\
\hline $\mathrm{N}$ & & 187 & 589 & \\
\hline Male & & $98(52.4 \%)$ & $332(56.4 \%)$ & 0.34 \\
\hline Age , median (IQR) & months & $3.6(1.0,7.1)$ & $4.0(1.3,7.6)$ & 0.35 \\
\hline Age of primary caregiver, median (IQR) & years & $25(21,31)$ & $25(21,31)$ & 0.87 \\
\hline Primary Caregiver $>35$ years & & $30(16.0 \%)$ & $89(15.1 \%)$ & 0.76 \\
\hline Started pacifier in the hospital & & $63(33.9 \%)$ & $296(50.5 \%)$ & $<0.001$ \\
\hline SIDS counseling at discharge & & $46(26.4 \%)$ & $270(49.5 \%)$ & $<0.001$ \\
\hline SIDS counseling in the clinic & & $39(22.3 \%)$ & $191(34.4 \%)$ & 0.003 \\
\hline $\begin{array}{l}\text { Number of bedrooms at home median } \\
\text { (IQR) }\end{array}$ & & $3(2,3)$ & $3(2,3)$ & 0.97 \\
\hline Number of other children, median (IQR) & & $1(0,3)$ & $2(1,3)$ & 0.72 \\
\hline Pacifier user at enrollment & & $64(34.2 \%)$ & $266(45.2 \%)$ & 0.008 \\
\hline \multicolumn{5}{|l|}{ Other recommendations known } \\
\hline Not in bed with adult & & $61(32.6 \%)$ & $405(68.9 \%)$ & $<0.001$ \\
\hline Sleeps on back & & $93(49.7 \%)$ & $516(87.6 \%)$ & $<0.001$ \\
\hline No smoking & & $99(53.2 \%)$ & $557(95.1 \%)$ & $<0.001$ \\
\hline Pacifier when sleeping & & $38(20.3 \%)$ & $230(39.2 \%)$ & $<0.001$ \\
\hline
\end{tabular}

\section{Caregivers should not smoke}

\section{Factor}

$\mathrm{N}$

Male

Age, median (IQR)

Age of primary caregiver, median (IQR)

Primary Caregiver $>35$ years

Started pacifier in the hospital

SIDS counseling at discharge

SIDS counseling in the clinic

Number of bedrooms at home median(IQR)

Number of other children, median (IQR)

Pacifier user at enrollment

$\begin{array}{llll} & \begin{array}{l}\text { Did not } \\ \text { know }\end{array} & \text { Knew } & \begin{array}{l}\text { p- } \\ \text { value }\end{array} \\ & 116 & 660 & \\ \text { month } & 68(58.6 \%) & 361(54.7 \%) & 0.43 \\ \text { s } & 3.4(1.0,6.7) & 4.0(1.3,7.6) & 0.23 \\ \text { years } & 26(21,33) & 25(20,31) & 0.064 \\ & 23(19.8 \%) & 96(14.5 \%) & 0.15 \\ & 47(40.9 \%) & 311(47.3 \%) & 0.20 \\ & 28(26.4 \%) & 289(47.1 \%) & <0.001 \\ & 24(22.0 \%) & 207(33.3 \%) & 0.020 \\ & 3(2,3) & 3(2,3) & 0.38 \\ & 2(1,3) & 1(0,3) & 0.21 \\ & 45(38.8 \%) & 282(42.7 \%) & 0.43 \\ & & & \\ & & & <0.001 \\ & 46(39.7 \%) & 422(64.0 \%) & <0.001 \\ & 61(52.6 \%) & 550(83.3 \%) & <0 \\ & 0(0.0 \%) & 660(100.0 \%) & <0.001 \\ 19(16.4 \%) & 246(37.4 \%) & <0.001\end{array}$




\section{Offer a pacifier when putting to sleep}

Factor

$\mathrm{N}$

Male

Age, median (IQR)

month
years

\section{Did not know} 509

$272(53.4 \%)$

$3.4(1.0,7.0)$

Age of primary caregiver, median (IQR)

Primary Caregiver $>35$ years

Started pacifier in the hospital

SIDS counseling at discharge

SIDS counseling in the clinic

Number of bedrooms at home

median(IQR)

Number of other children, median (IQR)

Pacifier user at enrollment

Other recommendations known

Not in bed with adult

Sleeps on back

No smoking

No blankets, stuffed animals
$25(21,30)$

74 (14.5\%)

$210(41.5 \%)$

$183(38.4 \%)$

$121(25.2 \%)$

$3(2,3)$

$1(1,3)$

$204(40.1 \%)$

$278(54.6 \%)$

$380(74.7 \%)$

$411(80.9 \%)$

356 (70.5\%)
Knew

268

$156(58.2 \%)$

$5.0(1.6,8.3)$

$26(21,31)$

45 (16.8\%)

$151(56.3 \%)$

$133(54.7 \%)$

109 (43.3\%)

$2(2,3)$

$2(1,3)$

$125(46.6 \%)$

189 (70.8\%)

$230(85.8 \%)$

$246(92.8 \%)$

$230(85.8 \%)$ p-value

0.20

0.001

0.19

0.41

$<0.001$

$<0.001$

$<0.001$

0.17

0.70

0.078

$<0.001$

$<0.001$

$<0.001$

$<0.001$ 


\begin{tabular}{|c|c|c|c|c|c|c|c|c|c|c|}
\hline & SDScounselling & SDScounsellingat & Started pacifier & Pacifier user & Efect per & Knew Recommendation & & & & \\
\hline Recoomendation known & at discharge $(95 \% \mathrm{~d})$ & dinic $(95 \% \mathrm{~d})$ & in hospital (95\% a) & at entry $(95 \% \mathrm{~d})$ & bedroom $(95 \% \mathrm{~d})$ & (A) $(95 \% \mathrm{~d})$ & (B) $(95 \% \mathrm{~d})$ & (C) $(95 \% \mathrm{~d})$ & (D) $(95 \% \mathrm{~d})$ & (日) $(95 \%$ d) \\
\hline (A) No cosleeping with adult & $1.57(1.08,2.29)$ & $1.84(1.21,2.80)$ & NS & NS & $1.19(1.00,1.41)$ & Referent & $3.31(2.14,5.12)$ & $2.63(1.74,3.98)$ & NS & $1.45(1.01,210)$ \\
\hline (B) Infant to sleep on back & NS & $1.83(1.11,3.00)$ & NS & NS & NS & $3.13(2.05,4.76)$ & Referent & $4.22(2.67,6.67)$ & $1.82(1.08,3.10)$ & NS \\
\hline (C) No stuffed toys/blankets in crib & NS & NS & $1.61,(1.04,2.49)$ & $1.60(1.03,2.46)$ & NS & $2.90(1.88,4.46)$ & $3.92(2.49,6.18)$ & Referent & $14.81(8.73,25.13)$ & NS \\
\hline (D) No caregiver smoking & NS & NS & NS & NS & NS & NS & NS & $15.30(9.51,24.62)$ & Referent & $2.10(1.19,3.72)$ \\
\hline (E) Offer a pacifier when sleeping & $1.53(110,2.13)$ & NS & $1.57(1.14,2.17)$ & NS & NS & $1.55(1.09,2.21)$ & NS & $1.78(1.16,2.74)$ & NS & Referent \\
\hline
\end{tabular}

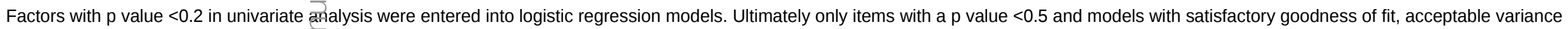
inflation factors, and without collinearity rvere retained.

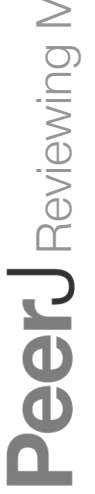

